\title{
Accessing Government Eye Care Services: Expriences of Children With Eye Health Conditions in Mubende, Uganda
}

\author{
Odette Tumwesigye Niyisabwa, Elijah Musenyente
}

Department of Community and Disability Studies, Kyambogo University, Uganda

Background: Apart from parents reluctance towards childrens early eye-care, government eye care services are costly, few ophthalmologists are in place, yet people suffering from eye infections are increasing. This study aimed to explore the response of parents towards exposing their children with eye health conditions to early eye care services, the efficiency of eye care services offered and the costs involved in accessing eye care services.

Subjects and Method: This was a qualitative study with in-depth interview. Conducted in Mubende, Uganda, from June 2019 to May 2020. A total of 12 informants were selected by purposive sampling. The data were collected using semi structured interviews from 12 participants involving children with eye health conditions and one (1) ophthalmic Officer (OCO). Investigator triangulation method was used whereby each participant was interviewed by more than one investigator as a way of obtaining several differing opinions concerning issues in question. The transcribed data were analyzed using content analysis.

Results: The findings indicated that, parental responsibility for children with eye health conditions for early assessment, diagnosis and treatment was generally lacking among fathers than among mothers. Poverty, illiteracy and ignorance among parents, use of traditional herbal treatment of eyes often resulted in serious consequences. Regarding efficiency, there were a lot of hardships in accessing the eye care services due to limited eye care centres, inadequate skilled or specialized personnel and irregular attendance by medical staff in government eye-care centres. The eye health care services were found to be expensive and unaffordable by the community.

Conclusion: The study concluded that overall, opportunities for visual assessment, diagnosis and treatment for children with eye health conditions in Mubende District were generally limited. Comprehensive eye care services that covers every member of the community are highly recommended.

Keyword.s: eye-care services, eye health conditions, Mubende-Uganda

\section{Correspondence:}

Odette Tumwesigye Niyisabwa. Department of Community and Disability Studies, Kyambogo University. Kyambogo Road, Kampala, Uganda. Email: niyisabwa.odette@gmail.com. Mobile: $+256772968235$

\section{Cite this as:}

Niyisabwa OT, Musenyente E (2021). Accessing Government Eye Care Services: Expriences of Children With Eye Health Conditions in Mubende, Uganda. J Health Promot Behav. 06(02): 122-132. https://doi.org/10.26911/thejhpb.2021.06.02.05.

cc (i) (2) Journal of Health Promotion and Behavioris licensed under a Creative Commons Attribution-NonCommercial-ShareAlike 4.o International License.

\section{BACKGROUND}

Uganda's Ministry of Health (MOH) has an obligation of providing quality health services for each person at every level of care in Uganda (Institute for Health Metrics and
Evaluation IHME, 2014). Melgar, Green (2019) argue that, Uganda government's assertion of providing eye-care at no cost is baseless because, eye-care within healthcare funding is not prioritized, resulting in 
its non-existence in some parts of the country.

The Ministry of Health (2016) provides guidelines for eye care management and diagnosis of seventeen types of eye infections in Uganda and define Eye Care Workers as health workers involved in delivery of eye services from village to district levels. The eye health workers deliver eyecare services at community, primary, secondary/district and tertiary levels (Kaggwa, 2014). Uganda has an increasing number of people who get cataracts or other eye infections. Data from Health Management Information System reveals that in Uganda, between 300,000 - 350,000 people completely lost their sight and became blind while over one million and two hundred people have visual impairment (Oysters and Pearls, 2020).

Brien Holden Foundation (2021) found out that one ophthalmologist in Uganda serves over one million people. A recent study indicates that, in southwestern Uganda for example, only 10\% of Eye Care Workers reported that they were routinely assessing people for glaucoma, indicating potential room for improvement (Magyezi and Arunga, 2020:48-50). Basing on such gaps in the eye care system, a random selection of districts in Uganda was carried out whereupon Mubende district was chosen for research to determine how eye care services can be accessed. It is therefore, upon this background that the study was grounded in Uganda's health service provision, Institute for Health Metrics and Evaluation (IHME) 2014. The study required health facility assessment in terms of perception of services attained by the patient, health care-costs and efficiency of service delivery.

Access to government health services including eye care health services is a right for all citizens in Uganda. This right is also recognized internationally as indicated in Public Health Reports (1999) portrayed in VISION 2020 as: "The Right to Sight, to eliminate avoidable blindness by 2020". (p.210). The World Health Organization (2007) provides that, the most important strategies to eliminate avoidable blindness is early detection and treatment; and more than $90 \%$ of visual impairments can either be treated or avoided if early assessment is done. Uganda has provided for this right through the (Children's Statute, 2016). The child shall be treated and given facilities to help him or her live as normal a life as possible. One of the strategies to implement the above right was through the Educational Assessment and Resource Services (EARS) program in 1993.

However, the benefits of the program did not last for long. When DANIDA pulled out its funding in 2001, the employees who were involved in making early identification of different conditions including eye health and thus early referrals to health centers were assigned other responsibilities in the districts. Currently, there is no other deliberate effort by government to conduct country wide identification of children with such conditions at grass root level. So, despite the national legislations in place, children with eye health conditions in Uganda communities are not adequately accessing visual assessment services in government health centers. Binder (2018), found out that $90 \%$ of the causes of blindness in Uganda are avoidable diseases as follows: glaucoma (10\%), trachoma and other forms of corneal scarring (30\%), cataract (50\%), and miscellaneous causes (10\%). Therefore, this study aimed to investigated access to government eye care services by exploring the experiences of children with eye health conditions in $\mathrm{Mu}$ bende, Uganda. 
Niyisabwa et al./ Accessing Government Eye Care Services in Uganda

\section{SUBJECTS AND METHOD}

\section{Study Design}

This study uses a qualitative design, used in-depth interview. Multiple cases were studied to understand the differences and similarities between cases and analyzed across different and within each situation (Gustafsson, 2017). Investigator triangulation method was used whereby each participant was interviewed by more than one investigator as a way of obtaining several differing opinions concerning issues in question.

This study was conducted in Mubende, Uganda from June 2019 to May 2020.

\section{Study Informants}

The collection of informants in this study uses purposive sampling, which is the technique of determining samples with certain considerations or criteria. The participants for the study were the Ophthalmic officers $(n=1)$ and children with eye health conditions $(n=11)$. Thus, a total of 12 participants includes for this study.

\section{Operational Definition of Variables} Eye health conditions Refers to vision problems which include eye diseases, infections and disorders that can easily lead to low vision and blindness if not well attended to in time.

Parental response Refers to the duty of parents being mindful, show interest and take responsibility about the eye health conditions of their child after identifying that there is something wrong with the eye health.

Efficiency of medical personnel is making the right eye assessment, diagnosis and treatment to improve the eye health condition of an individual by medical eye care staff.

Costs involved is the medical fee meant for eye health condition assessment, diag- nosis, surgery and treatment meant to improve the eye health.

Health facilities are designated as Health Centre level one (HC I) to Health Centre Level four (HC IV); General hospital, Regional Referral hospital and National Referral hospital. There are 14 Regional Referral Hospitals (RRHs) and 139 are General Hospitals (GHs) in the country. The exclusion criteria in this study were

\section{Data Analysis}

Data analysis in this study uses content analysis. These themes can be identified, coded inductively (data driven) from raw qualitative data (interview transcripts, biographies, video recordings, etc.) as well as deductively (theory driven) based on theory and the results of previous study. In this study only uses one type of analysis, namely cotent analysis.

Data was collected using semi structured interviews. In-depth interviewes were administered to the participants, ie one opthalmic officer of the referral hospital and eleven children with eye health conditions. Interviews sessions of about 45 minutes were conducted. An audio recorder was used in recording interviews and a note-book used for recording the information. Data was organized under different themes and relevant research objectives.

\section{RESULTS}

\section{Response of parents}

The study found out that parental responsibility of taking their children with eye health conditions for early assessment, diagnosis and treatment was generally lacking. For example, whenever child number three told his father about his eye condition, he (father) usually consulted the step-mother whether to take the child to the hospital or not. The step-mother often discouraged him from taking the child to hospital thus: 
Niyisabwa et al./ Accessing Government Eye Care Services in Uganda

"She tells my father that I have

no problems with the eyes since I

can do everywork at home."

The study also found out that the responsibility to take children with eye health conditions was lacking among fathers than among mothers. All the children interviewed testified that, they were taken to hospital by their mothers. Child seven crowned it all when she said that:

"I was taken to the hospital for eye treatment by my mother but my father had no idea that I had a problem with the eyes.'

The study also found out that, in addition to failure to pay for medical expenses and inability to accompany their children to hospital, parental neglect by fathers towards their children with eye conditions was also evident in their refusal to provide transport facilitation as lamented by child ten thus:

"My father refused to give me money for transport to the health centre, and since he is the only breadwinner in the family, when he refuses something, his decision is considered to be final. To make matters worse, my father has another wife and its where he stays."

The study identified that poverty, illiteracy and ignorance were also key factors in preventing parents towards exposing their children with eye health conditions to early eyecare services. Instead, parents resorted to traditional mehods of eye care which included the use of local herbs and sacrifices to gods which worsen the eye conditions of their children. Risky examples include the use of urine for eye treatment which creates a risk of worsrning the condition as narrated by child one:
"My mother tells me to wash my face using urine every morning, but I still hve no improvement"

Child eight's experience was thus:

"It started when my eyes became red, so my mother got some herbs and dropped in my eyes. From that day, the red eyes cleared but after some time, I could not see clearly. I was taken to Mumbende Hospital to see the doctors. When the doctors assessed me, I was told that I needed surgery on one eye as the herbs had worsened its condition.

Further due to poverty, illiteracy and ignorance study found out that children were discouraged from accessing eye care services by family members who gave excused that: eye doctors do not work on particular days, there are no machines used for checking the eye conditions, and that the service take a lot of money. The study also discovered some elements of self-prejudice among children who had given up on accessing treatment, to the extent that some of them feared even revealing to their parents or guardians about the eye conditions due to their rudeness. This is evident in child eleven's expression:

"I have never gone for vision assessment and have never informed my parents about the eye condition because they are rude, I fear to be beaten. Also, my mother's husband is not my real father but a step father. The step father usually tells me to drop out of school and stay at home digging. I have been experiencing mistreatment including denial offood and books"

The study also revealed that parental attitude towards the treatment of eye prob- 
lems of their childrens was not a priority compared to other diseases like for example measles as reported by chid five that:

"My grandmother always told me that she had no money to take me for eye treatment, yet she always took alchol every day. One time she inquired about where she could take me so that they can treat the eyes but did not take me there."

The study found out that delay and constant failure to access eye services worsened the eye health conditions of children and often affected their sight. The effect on the children's sight possed serious consequences to their education for example difficulty in reading and writing. This resulted in some children dropping out of school as expressed by child eight, thus:

"I can see bright colors only in the morning especially the white color. I found difficulty in reading and writing, so I dropped out of school"

However, the study found out that, although some children with eye health conditions faced challenges like tears coming out of their eyes when reading, seeing objects at a distance and inability to see what the teacher writes on the blackboard, they persisted and adapted some copying strategies as evident from the children's own words as follows:

Child six:

"Now my sight has reduced so much and I find it difficult to copy work from the chalkboard.

I usually copy work from my friend."

Child seven:

"I seat in front in the classroom to enable me see what the teacher teaches and write at the blackboard."
Child seven's words are echoed and confirmed in Child nine's lamentation thus:

"I still have a problem in seeing what the teacher has written on the blackboard, and when I try to write, tears always come from my eyes."

\section{Efficiency of government eye care services}

The study sought to find out the efficiency of government eye-care services offered in Mubende district. It found out that there was a lot of hardships in accessing the eye care treatment due to limited eye care centers and specialized personnel within $\mathrm{Mu}$ bende district. Some of the available health centers like clinics did not have specialized eye care staff to cater for children's eye conditions. Child five said that:

"I have never gone for eye checkup or treatment. Where we stay, there is no government hospital where I can get free treatment, but there are only clinics"

The hardship in accessing eye-care services in Mubende district is evident from the lamentations of child two who said that:

"The line was long and people who needed to see the doctor were so many. I was in much pain but the doctors were shouting at people and this made me and my mother so scared to wait and tell them how I was feeling. I couldn't even see the doctor that time. We waited from 8:00 am to 2:0opm and we gave up and went back home"

"On return to the hospital, we found a lot of people and we didn't get the opportunity to see the doctor. Up to now, we have never gone back to the hospital" 
The above situation indicates a situation of hopelessness and often leads to frustration and giving up. The study also found out that Nurses / doctors were being given extra training on eye care and thus added extra duties in addition to their usual duties. However, their pay remained constant. This demoralized them from doing their work efficiently.

In addition, the attendance of the eye care staff in government eye care centers was irregular. For example, child ten expressed that:

"The opticians come to the health center only once in a month"

The study also learnt from one of the participants that, eye health condition was not given priority in terms of adequate facilitation as per the words of one health official thus:

"Eye health condition is not a killer disease. Therefore, the Ministry of Health does not give it priority."

The study found that some staff did not have adequate skills in eye health conditions both in private clinics and government regional referral hospitals as expressed by child one below:

"I went to the hospital (regional referral hospital) with my_mother and the doctor assessed me and said that I am short sighted. He gave me Panadol plus other tablets and said that I was going to be well."

Even on occasions when the regional referral hospital organizes an annual one day's mass eye assessment and treatment for all children with eye conditions, the eye care specialists are usually not sufficient; as expressed by child four below:

"I turned up for the mass eye assessment organized for children every year, but the doctors were spending on each person a very short time, and it was difficult to explain what I was experiencing"

\section{Medical Costs}

The findings of the study revealed that, eye health services are expensive and not affordable by the community. The high costs were preventing some members of the community from accessing the services. For example, one of the children paid UGX. 18.000 (approximately US\$5) to access treatment. The study also identified that, even those referred to bigger government hospitals for better treatment were required to pay some fee referred to as (cost sharing fee) as expressed by child two:

"The treatment cost UGX 5,Ooo (\$1.5)"

Failure to pay and attain appropriate eye care services in good time worsens the eye health condition of an individual, as expressed by child one. For example, child one said that, she acquired blindness after missing an eye operation because her parents could not raise UGX 3,00o" (about one USD) to transport her to the hospital. The study also found out that, the high unaffordable medical expenses and costs of assistive devices (like eye glasses) resulted in some children with eye health conditions giving-up on treatment as expressed by child one thus:

"We went back to the clinic with my mother and the nurse told us that we had to go to a bigger hospital. She also told us that I should stop using the eye drops. During that period of time, that's when I lost my father who could have raised some money for my treatment. So, I have never gone for treatment from any hospital" The study discovered that some children got the opportunity of being assessed 
but were unable to get money for treatment and buy glasses. Even the annual one-day mass service organized by regional hospitals for eye care for children, and meant to be free; the fee exemption was only meant for consultation only, but treatment and glasses were charged expensively. According to the words of child four:

"On the mass assessment, they assessed every one for free, I was told to first pay 30.000 Uganda Shillings (approximately $\$ 10$ ) for both the medicine expenses and glasses, yet I came knowing that I was to be given everything free on that day. When I told my parents, they could not raise that money"

Like child four mentioned above, other children like child nine experienced similar challenges thus:

"I was taken by my mother to the hospital. I was given eye drops to use for some time and was told I need spectacles to correct my vision. My mother had no money to buy the spectacles, so we never went back to the hospital."

Even the few available clinics with eye care services were very expensive as stated by child five:

"I stay with my grand mother who can not afford the costs. The hospital that gives free medicine is in town and it is very far for my grandmother to take me there. She always tells me that she has no money for transport to the hospital.

The above statement is also supported by child seven who said that:

"I was not given any medicine at the hospital, they recommended to my mother to buy it from the drug shop. My mother had only transport left with her, so I never received any treatment."

The study established that even in government eye care centers where services are subsidized to a very minimal amount, some members of the community are so poor that they could not afford the costs. This was expressed by child six:

"I realized that my sight was reducing so much and I could not be able to read well. I requested my father to take me to the hospital. When he took me there, the doctor examined my eyes and told us that I had a cataract. It was in the month of February and he told us to go for an eye operation after 6 months (in August). When time came for going for the operation, I reminded my father and he told me that he had no transport to take me to the hospital (10,0oo Uganda shillings) approximately 3 USD"

In addition to the specific objectives of the study, other factors concerning parental eye-care for their children were discovered. These included the fact that most of the children who were affected by eye conditions had poor nutrition.

\section{DISCUSSION}

\section{Respon of Parents}

The study's findings concerning lack of parental responsibility for taking their children with eye health conditions (Mbonye, 2003. in some rural areas of Uganda parents attitude towards the treatment of their children's diseases including eye conditions is low. The study's identification of poverty, illiteracy and ignorance as being key factors in preventing parents towards 
exposing their children with eye health conditions to early eye-care services (Sudharsanam \& Rotti, 2007) preventing parents from seeking eye care for their children. These included medical expenses, difficulties in accessing doctors, the attitude of parents towards treating eye conditions, and lack of awareness by the community on the effects of untreated eye conditions. Acton (2011) contends that coming from rural areas as well as low socio-economic status, coupled with illiteracy and ignorance, leads to lack of proper eye care. Hugenholtz et al., (2009) argue many parents tend to take their children for medication in eye care centres not because of the eye condition itself but after failing to treat them in their homes especially using local herbs.

While the study revealed that parental attitude towards the treatment of eye problems of their childrens was not a priority compared to other diseases like measles; (Taffa and Chepngeno, 2005) previous study found that eye health conditions were not perceived as serious like diarrhea. Parents especially those from rural areas, needed awareness and sensitization on early intervention of their children's eye health conditions (Senthilkumar et al., 2013). The study findings that delay in accessing medical attention for eye health conditions by children leads to serious effects. Agrees et al., (2003) previous study that early intervention by parents prevents severe effects of visual impairment.

\section{Efficiency of Government eye care services}

The study discovered a lot of hardships in accessing the eye care treatment due to limited eye care centers and specialized personnel. The difficulties in obtaining appointments from doctors as well as other preventive factors like interferences from family and scarcity of treatment are obstacles to accessing eye health care services
(Ebeigbe, 2016). The study found out that the eye-care medical staff were demotivated by being added extra duties in addition to their usual duties without additional payment. Bechange, Jolley, Virendrakumar, Pente, Milgate and Schmidt (2020) argue that, lack adequate renumeration adversily affected staff ability and morale to work efficiently.

The study discovered that, some of the eye care staff in government eye-care centres were few and insufficient, less skilled and inefficient in addition to their irregular duty attendance. While Uganda was capable of meeting the VISION (2020) target of four surgeons, physician cataract surgeons and ophthalmologists per million population, the rate of cataract surgery is minimal and there is need for more eye care providers to be trained as well as purchase ophthalmic equipment, (Palmer et al., 2014).

\section{Medical Costs}

The study revealed that, eye health services are costly and not affordable by the community. Inability of affording eye health services was also associated with poverty among the communities. Ebeigbe (2016) identified medical expenses as the major factor in preventing parents from taking their children for eye care services. Andre (2016) also suggests poverty as one of the major causes of failure to access eye treatment in Africa. Other causes include lack of awareness of existing services especially for people in remote places. However, the study also found out that some parents were not willing to pay for eye care services for their children partly because of poverty but also due to negative attitudes towards their children with eye health conditions.

The study also identified that, in addition to the high unaffordable medical expenses, assistive devices (like eye glasses) were equally costly. However, the Ugandan 
government claims that the provision of eye care is free of charge yet it is not a priority and so has limited funding to the extent that in some locations, there are no eye care services (Geneau et al., 2008). Further, Ibrahim et al., (2008) argue that, even in Uganda where eye care services in public hospitals are claimed to be free of charge, there exists some obstacles in using existing services because clients are required to make some contributions for example, towards the Cataract Surgeon's transport cost.

In conclusion, the study investigated access to government eye care services by exploring the expriences of children with eye health conditions in mubende district. The study concluded that early intervention by parents and government prevents severe effects of visual impairment which leads to blindness and recommended that, awareness programs should be designed for assisting and sensitizing parents in addressing barriers that prevent them from obtaining their childrens eye care services. Although eye health cannot lead to death (like cholera, ebola and others), the government of Uganda in its budgets should also give it priority. Comprehensive eye care services that covers every member of the community are highly recommended.

\section{AUTHOR CONTRIBUTION}

Niyisabwa Odette Tumwesigye designed the study, collected the data, provided intellecttual content. Musenyente Elijah collected the data, provided intellectual content, writing report of the research.

\section{FUNDING AND SPONSORSHIP}

This research supported by NORHED ENABLE project as part of the small-scale research grants. The project was attached to the department of Special Needs Studies, in the faculty of Special Needs and Rehabilitation at Kyambogo University.

\section{CONFLICT OF INTEREST}

There is no conflict of interest in this study.

\section{ACKNOWLEDGMENT}

We are grateful to NORHED ENABLE project for the financial support. We also grateful to the children with visual impairments and their parents who contributed useful information for this study.

\section{REFERENCES}

Acton A (2011). Vision Disorders: Advances in Research and Treatment. Atlanta, Georgia: Scholarly Editions.

Amiebenomo OM, Achugwo DC, Abah I (2006). Parental knowledge and attitude to childrens eye care services. Niger. J. Paediatr. Vol. 43, No. 3:217. DOI: $10.4314 /$ njp.v43i3.11

Andre JM (2016). Africa needs a sustainable solution to deal with cataract blindness. School of Medicine, AixMarseille Université (AMU).

Baviskar K (2006). Nature Cure in Eye Care. New Delhi: B. Jain Publishers (P) Ltd.

Bechange S, Jolley E, Virendrakumar B, Pente V, Milgate, J, Schmidt E (2020). Strengths and weaknesses of eye care services in sub-Saharan Africa: a meta-synthesis of eye health system assessments. volume 20, Article number: 381. DOI: https://doi.org/10.1186/s12913-020-05279-2

Binder SP (2018). Uganda: Creating sustainable eyecare. International Presentation spotlight. EyeWorld. https://www.eyeworld.org/

Brien Holden Foundation (2021). Why optometry for uganda? Kampala. Brien Holden Foundation Publica- 
Niyisabwa et al./ Accessing Government Eye Care Services in Uganda

tions.

Ebeigbe JA (2016). Factors influencing eye-care seeking behaviour of parents for their children in Nigeria. DOI: https://doi.org/10.1111/cxo.12506

Ezegwui IR, Umeh RE, Ezepue UF (2003). Causes of childhood blindness: results from schools for the blind in South Eastern Nigeria. Br. J. Ophthalmol; 87: $20-23$.

Geneau R, Massae P, Courtright P, Lewallen $S$ (2008). Using qualitative methods to understand the determinants of patients willingness to pay for cataract surgery: a study in Tanzania. Soc Sci Med. 66:558-68. DOI: 10.1016/j.socscimed.2007.09.016.

Gustafsson J (2017). Single case studies vs. multiple case studies: A comparative study. Halmstad: Academy of Business, Engineering and Science, Halmstad University.

Hugenholtz M, Broer C, Van Daalen R (2009). Apprehensive parents: a qualitative study of parents seeking immediate primary care for their children. Br J Gen Pract 2009; 59: 173179. DOI: https://doi.org/10.3399/bjgpo9X394996

Ibrahim N, Pozo-Martin F, Gilbert C (2008). Direct non-medical costs double the total direct costs to patients undergoing cataract surgery in Zamfara state, Northern Nigeria: a case series. BMC Health Serv Res. 2015.15:163. DOI: https://doi.org/10. 1186/s12913-015-0831-2

Institute for Health Metrics and Evaluation - IHME (2014). Health Service Provision in Uganda: Assessing Facility Capacity, Costs of Care, and Patient Perspectives. Seattle, WA: IHME.

Kaggwa G. (2014). Ophthalmic clinical officers: developments in Uganda. Community eye health, 27(86), 34 .
Kovai V, Krishnaiah S, Shamanna BR (2007). Barriers to accessing eye care services among visually impaired populations in rural Andhra Pradesh, South India. Ind J Ophthalmol 2007; 55: 365-371. DOI: 10.4103/0301-4738.33823 .

Magyezi J, Arunga S (2020). Eye care where there are no ophthalmologists: the Uganda experience. Community eye health journal, volume 33 , number 110:48-50.

Mbonye AK (2003). Prevalence of childhood illness and care seeking practices in rural Uganda. Science World Journal. 19:721-730. DOI: https://doi.org/10.1100/tsw. 2003.52

Ministry of Education and Sports - MOES (1994). Awareness course in Special Education. Kampala: Government of Uganda.

Ministry of Health (2016). Guidelines for eye care. Kampala: $\mathrm{MOH}$ publications.

Oysters and Pearls Uganda (2020). Help for Ugandan Blind. Kampala-Oysters and Pearls. http://www.oystersandpearls.o.rg Retrieved 27th March, 2021

Palmer JJ, Chinanayi F, Gilbert A (2014). Mapping human resources for eye health in 21 coun-tries of sub-Saharan Africa: current progress towards VISION 2020. Hum. Resour. Health. 12:44. DOI: $10.1186 / 1478-4491-12-44$

Public Health Report (1999). Public Health Reports: Evanston: Northwestern University, No. 1, Volume 114.

Ravilla T, Courtright P. Melgar JFY, Green D (2019). Affordability and Financing for Eye Care. Springer Nature Switzerland. https://www.researchgate.net/publication/ $\neg 329626713$. Retrieved 30th march 2021

Schwab L (2007). Eye Care in Developing Nations. Boca Raton, Francis and 
Niyisabwa et al./ Accessing Government Eye Care Services in Uganda

Taylor Group, CRC Press. DOI: https://doi.org/10.1201/b15129

Senthilkumar D, Balasubramaniam SM, Kumaran SE (2013). Parents' awareness and perception of childrens eye diseases in Chennai, India. Optom Vis Sci 2013; 90: 1462-1466. DOI: 10.1097/OPX.0000000000000084.s.

Sudharsanam MB, Rotti SB (2007). Factors determining health-seeking behaviour for sick children in a fishermen community in Pondicherry. Ind $\mathrm{J}$ Commun Med 2007; 32: 71- 72. DOI: 10.4103/0970-0218.53411.

Taffa N, Chepngeno G (2005). Determinants of health care seeking for childhood illnesses in Nairobi slums.
Trop Med Int Health 2005; 10: 240245. DOI: $10.1111 /$ j.1365-3156.2004.01381.x.

The children statute (2016). The Republic of Uganda: The children statute. Kampala: Parliament of Uganda. Accessed at ILOhttps://www.ilo.org. ELECTRONIC UGA104395. Retrieved 5th April, 2021

Vision (2020). Vision 2020: The right to sight. (Accessed March 15, 2021, at http://www.vision2020.org/main.cf $\mathrm{m})$.

World Health Organization (2007). Vision 2020: The Right to Sight. Global initiative for the elimination of avoidable blindness. Action plan 2006-2011. 